\title{
Intraoperative Differential Diagnosis: Double Gallbladder or Serous Cyst in the Gallbladder Bed?
}

\author{
Marian Botoncea, Vlad-Olimpiu Butiurca, Călin Molnar \\ Clinic of Surgery I, County Emergency Clinical Hospital, Tîrgu Mureș, Romania
}

\section{CORRESPONDENCE \\ Vlad-Olimpiu Butiurca \\ Str. Gheorghe Marinescu nr. 38 \\ 540139 Tîrgu Mureș, Romania \\ Tel: +40744152022 \\ E-mail:vladbutiurca@yahoo.com}

\section{ARTICLE HISTORY}

Received: June 11, 2017

Accepted: July 20, 2017
Marian Botoncea • Str. Gheorghe Marinescu nr. 38 540139 Tîrgu Mureș, Romania. Tel: +40 758468909 E-mail: botonceam@gmail.com

Călin Molnar • Str. Gheorghe Marinescu nr. 38 , 540139 Tîrgu Mureș, Romania. Tel: +40 722696610 E-mail:molnar.calin@yahoo.com
We present the case of a 61-year-old female patient, who was admitted in the Clinic of Surgery I of the County Emergency Clinical Hospital of Tîrgu Mureș in May 2017, presenting with the following complaints: intermittent abdominal pain located in the right upper quadrant, nausea, and vomiting, which started approximately one year before. Until hospital admission, several ultrasounds were performed in outpatient conditions, in a gastroenterology clinic, showing uncertain diagnoses such as asymptomatic gallbladder with serous hepatic cyst compressing the cystic duct; serous hepatic cyst with split gallbladder; double gallbladder or gallbladder diverticulum. The clinical examination revealed a positive Murphy sign. The liver function and biological laboratory tests were normal. Abdominal computed tomography revealed a normal liver with a cystic lesion apparently developed in intimate contact with the gallbladder, with an elongated shape, having dimensions of $65 \times 64 \times 48$ $\mathrm{mm}$ and cholelithiasis. After a short biological and anesthesiology preoperative preparation, we performed a laparoscopic "monobloc" cholecystectomy with ideal cystectomy, using an electrothermal bipolar sealing device (LigaSure Maryland ${ }^{\mathrm{TM}}$ ) for the lithiasic gallbladder, which was inserted directly in a serous hepatic cyst (Panel A). During the preparation of the Calot triangle, we found only one cystic duct (Panel B) and one cystic artery (Panel C). The gallbladder and the cyst were extracted "en bloc" (Panel D). Upon visual examination, we noticed two united cavities filled with different liquids: bile in the anterior cavity (gallbladder) and serous liquid in the posterior one (serous hepatic cyst). Apparently, these entities had no communication which each other; this was confirmed by the anatomopathological examination (chronic gallbladder lithiasis with extensive fibrosis in the fibromuscular layer, which comes into intimate contact with the serous hepatic cyst). The postoperative evolution of the patient was favorable, and she was discharged in the second day after surgery.

The treatment options of serous hepatic cyst include percutaneous drainage with sclerotherapy, surgical cystectomy, or marsupialization. ${ }^{1-4}$ In this case, the 

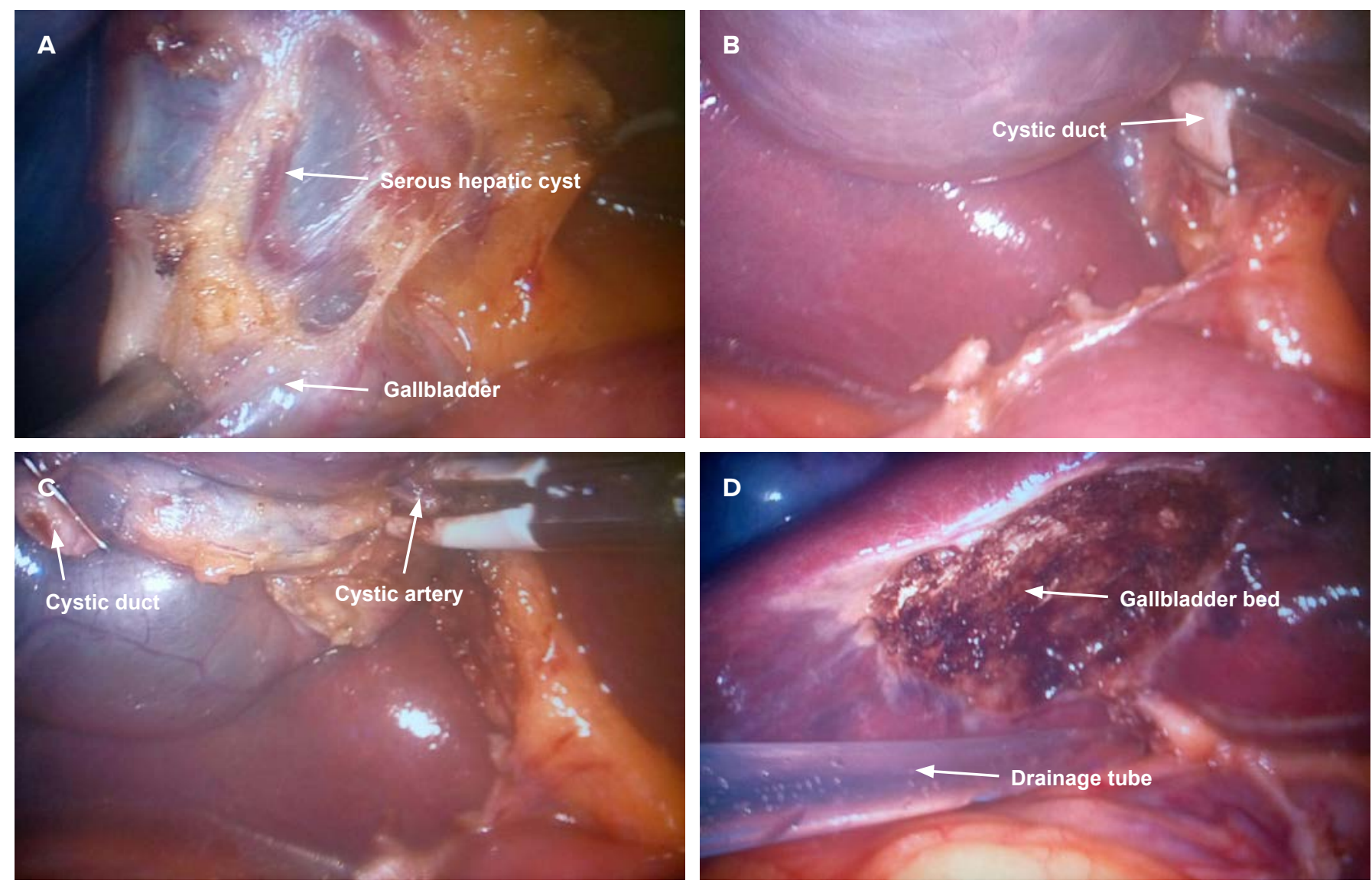

surgical approach was for a monobloc removal of both the cyst and the gallbladder for an ideal treatment.

The patient agreed to the publication of her data, and the institution where the patient had been admitted, approved the publication of the case.

\section{REFERENCES}

1. Benhamou J, Menu Y. Nonparasitic cystic disease of the liver and intrahepatic biliary tree. In: LH Blumgart, ed. Surgery of the liver and biliary tract. Edinburgh/UK/Churchill Livingstone; 1994. p. 1197-1210.

2. Moorthy K, Mihssin N, Houghton PW. The management of simple hepatic cysts: sclerotherapy or laparoscopic fenestration. Ann R Coll Surg Engl. 2001;83:409-414.

3. Wijnands TF, Görtjes AP, Gevers TJ, et al. Efficacy and Safety of Aspiration Sclerotherapy of Simple Hepatic Cyst: A Systematic Review. AJR Am J Roentgenol. 2017;208:201-207.

\section{CONFLICT OF INTEREST}

Nothing to declare.

4. Debs T, Kassir R, Reccia I, et al. Technical challenges in treating recurrent non-parasitic hepatic cysts. Int J Surg. 2016;25:44-48. 